\title{
Low-grade myofibroblastic sarcoma arising in the tip of the tongue with intravascular invasion: A case report
}

\author{
YURIE MIKAMI $^{1,2}$, SHINSUKE FUJII ${ }^{1}$, KEN-ICHI KOHASHI ${ }^{3}$, YUICHI YAMADA ${ }^{3}$, MASAFUMI MORIYAMA $^{2}$, \\ SHINTARO KAWANO $^{2}$, SEIJI NAKAMURA ${ }^{2}$, YOSHINAO ODA ${ }^{3}$ and TAMOTSU KIYOSHIMA ${ }^{1}$ \\ ${ }^{1}$ Laboratory of Oral Pathology and ${ }^{2}$ Section of Maxillofacial Oncology, Division of Maxillofacial Diagnostic \\ and Surgical Sciences, Faculty of Dental Science, Kyushu University; ${ }^{3}$ Department of Anatomic Pathology, \\ Graduate School of Medical Sciences, Kyushu University, Higashi-ku, Fukuoka 812-8582, Japan
}

Received March 24, 2018; Accepted June 28, 2018

DOI: $10.3892 / \mathrm{ol} .2018 .9115$

\begin{abstract}
Low-grade myofibroblastic sarcoma (LGMS) is a rare intermediate tumor, which rarely metastasizes and has myofibroblastic differentiation in various sites. It is particularly associated with the tongue in the head and neck region. The lack of any pathological features means it is difficult to make a conclusive diagnosis of LGMS. The immunohistochemical features and genomic rearrangements, including SS18-SSXs and MYH9-USP6s and the genetic mutations of cancer-associated genes, including APC, CTNNB1, EGFR, KRAS, PIK3CA and $p 53$ were examined in a case of LGMS arising in the tip of the tongue. Immunohistochemically, the tumor cells were positive for alpha-smooth muscle actin and vimentin, as in previous reports. They demonstrated neither genomic rearrangements nor point mutations of cancer-associated genes. Although several tumor cells demonstrated intravascular invasion, the MIB-1 labeling index of the cells was the same as the original lesion. To the best of our knowledge, this is the first case report of LGMS arising in the tip of the tongue with intravascular invasion.
\end{abstract}

\section{Introduction}

Low-grade myofibroblastic sarcoma (LGMS) is a rare sarcoma tumor. Atypical myofibroblasts have been shown to be involved in LGMS, such as in the femur (1), vulva (2) and phalanx (3). In the head and neck region, LGMS frequently occurs in the tongue (4). Myofibroblasts, which show characteristics of both fibroblasts and smooth muscle cells, were

Correspondence to: Professor Tamotsu Kiyoshima, Laboratory of Oral Pathology, Division of Maxillofacial Diagnostic and Surgical Sciences, Faculty of Dental Science, Kyushu University, 3-1-1 Maidashi, Higashi-ku, Fukuoka 812-8582, Japan

E-mail: kiyo@dent.kyushu-u.ac.jp

Key words: low-grade myofibroblastic sarcoma, intravascular invasion, genomic rearrangements, genetic mutations, tip of the tongue firstly identified in granulation tissue in 1971 (5). Fibroblasts differentiate into myofibroblasts during wound healing and tissue repair (6). According to the 2013 World Health Organization (WHO) classification (7), LGMS is categorized as a fibroblastic/myofibroblastic tumor; intermediate tumors (rarely metastasizing). Clinically, LGMS has a propensity for local recurrence and is associated with a low risk of metastatic spread. Immunohistochemically, LGMS tumor cells are positive for at least one myogenic marker, such as alpha-smooth muscle actin ( $\alpha$-SMA), desmin or muscle actin (HHF-35). As no definitive markers of LGMS have been found to date, it is difficult to make a diagnosis based on the pathological findings alone. In addition, whether or not the genetic mutations of cancer-related genes shown in sarcomas are involved in LGMS is unclear.

In the present study, we carried out immunohistochemical analyses in LGMS arising in the tip of the tongue in a sporadic case, examined genomic rearrangements, such as SS18-SSXs (SS18-SSX1, SS18-SSX2, SS18-SSX4, SS18-SSX4V, SS18p-SSXp or SS18-SSXp) and MYH9-USP6s (MYH9 exon 1 and USP6 exon 1 or MYH9 exon 1 and USP6 exon 2) for differential diagnostic supports and investigated whether or not these LGMS tumor cells harbored point mutations in the $A P C, C T N N B 1, E G F R, K R A S, P I K 3 C A$ and $p 53$ genes for detection of the malignant tumor behavior.

\section{Case report}

A 38-year-old woman visited at the Department of Oral and Maxillofacial Surgery at Kyushu University Hospital (Fukuoka, Japan) with a 2-month history of a painless mass showing gradual growth in the tip of the tongue (Fig. 1A). An oral examination revealed that the tumorous mass was soft-elastic and well-circumscribed, and the overlying mucosal surface showed redness and a normal texture. There was no clinical evidence of cervical lymphadenopathy. She had a medical history of idiopathic thrombocytopenic purpura (cured) and fibroma of her right breast (under observation). An ultrasonogram examination revealed that the mass had a hypoechoic area with undetectable vascularization (Fig. 1B). Based on these findings, the tumorous mass was clinically diagnosed as not a malignant tumor. An excisional biopsy was performed (Fig. 1C and D), 
Table I. Forward and reverse primers for genomic rearrangement analysis.

\begin{tabular}{|c|c|c|}
\hline Gene & Primer sets & Product size $(b p)$ \\
\hline \multirow[t]{2}{*}{ SS18-SSX1 } & F: 5'-AGACCAACACAGCCTGGACCAC-3' & 151 \\
\hline & R: 5'-GGTGCAGTTGTTTCCCATCG-3' & \\
\hline \multirow[t]{2}{*}{ SS18-SSX2 } & F: 5'-AGACCAACACAGCCTGGACCAC-3' & 109 \\
\hline & R: 5'-GCACTTCCTCCGAATCATTTC-3' & \\
\hline \multirow[t]{2}{*}{ SS18-SSX4 } & F: 5'-AGACCAACACAGCCTGGACCAC-3' & 113 \\
\hline & R: 5'-TCTGGCACTTCCTTCAAACC-3' & \\
\hline \multirow[t]{2}{*}{ SS18-SSX4V } & F: 5'-AGACCAACACAGCCTGGACCAC-3' & 119 \\
\hline & R: 5'-CCAGCTGCTTTCTCTTACGC-3' & \\
\hline \multirow[t]{2}{*}{ SS18p-SSXp } & F: 5'-CCAGCAGAGGCCTTATGGATA-3' & 98 \\
\hline & R: 5'-TTTGTGGGCCAGATGCTTC-3' & \\
\hline \multirow[t]{2}{*}{ SS18-SSXp } & F: 5'-AGACCAACACAGCCTGGACCAC-3' & 130 \\
\hline & R: 5'-TTTGTGGGCCAGATGCTTC-3' & \\
\hline \multirow[t]{2}{*}{ MYH9 (exon 1)-USP6 (exon 1) } & F: 5'-GGGGCAGATCCAGGTTCAG-3' & 120 \\
\hline & R: 5'-GAAACTGGGCATCTCTGTGGC-3' & \\
\hline \multirow[t]{2}{*}{ MYH9 (exon 1)-USP6 (exon 2) } & F: 5'-GGGGCAGATCCAGGTTCAG-3' & 122 \\
\hline & R: 5'-GATGGACATGGTAGAGAATGC-3' & \\
\hline
\end{tabular}

Annealing for all polymerase chain reaciton products was performed at $62^{\circ} \mathrm{C}$. F, forward; R, reverse.

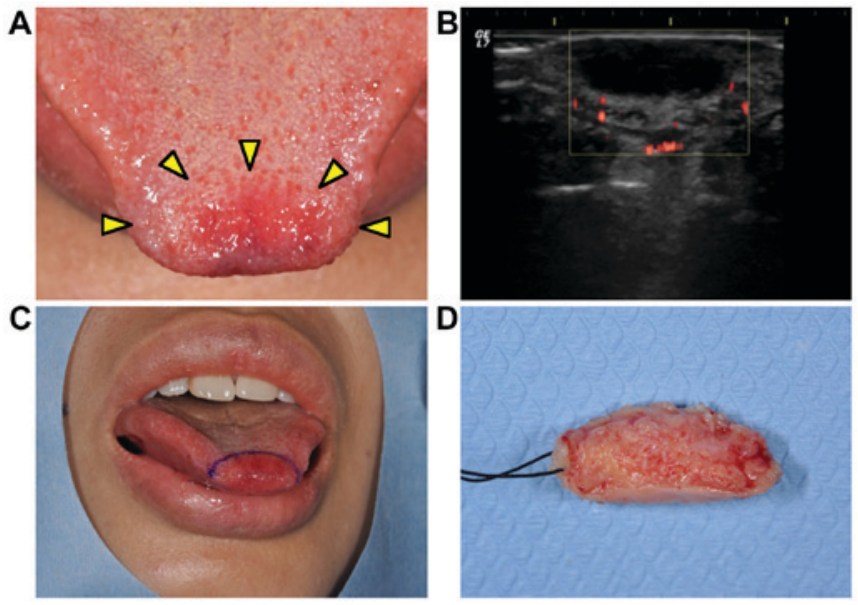

Figure 1. (A) A macroscopic photo of the tongue at the initial visit. The well-circumscribed elastic soft, $15 \times 10 \times 5 \mathrm{~mm}$ mass was overlaid with mucosa showing the redness of the surface. The yellow triangles indicate the boundary of the mass. (B) An ultrasonogram examination revealed that the mass was a $13 \times 5 \mathrm{~mm}$ hypoechoic area with undetectable vascular flow. An excisional biopsy was performed. (C) The incision line indicates the resection of the tumorous mass with 2-3 mm normal tissue. (D) Following resection the surface was shown.

and the mass showed proliferation of spindle-shaped cells with fascicular and/or storiform patterns in the subepithelial nodular tumor lesion (Fig. 2A). Nuclear pleomorphism was shown in the tumor cells. The number of mitotic figures was $<1$ per 10 high-power fields (Fig. 2B).

Immunohistochemical examination was performed as described below. Paraformaldehyde-fixed paraffin-embedded (PFPE) tissues were cut at $4-\mu \mathrm{m}$ thickness. Immunohistochemical staining was performed using BondIII (Leica Microsystems GmbH, Wetzlar, Germany) according to the manufacturer's instructions in the Division of Diagnostic Pathology in Kyushu University Hospital. The following monoclonal antibodies were used: Mouse anti-AE1/AE3 (1:100; cat. no. M 3515; Agilent Technologies, Inc., Santa Clara, CA, USA), mouse anti-EMA (1:100; cat. no. M 0613; Agilent Technologies, Inc.), mouse anti-CAM5.2 (1:100; cat. no. 349205; BD Biosciences, Franklin Lakes, NJ, USA), mouse anti- $\alpha$-SMA (1:500; cat. no. M 0851; Agilent Technologies, Inc.), mouse anti-CD34 (1:1,000; cat. no. PA0212; Leica Biosystems, Wetzlar, Germany), mouse anti-MIB-1 (1:100; cat. no. M 7240; Agilent Technologies, Inc.), and mouse anti-vimentin (1:5; cat. no. 760-2512; Ventana Medical Systems, Inc., Tucson, AZ, USA). Immunohistochemical staining was also performed with the universal immunoperoxidase polymer method (Envision-kit; Agilent Technologies, Inc.) using monoclonal mouse anti-BAF47 (INI1 gene product) (1:250; cat. no. 612110; BD Biosciences) antibody. Immunohistochemical analyses showed that the spindle-shaped cells were positive for $\alpha$-SMA (Fig. 2C) and vimentin (Fig. 2D) and negative for epithelial markers; AE1/AE3, EMA and CAM5.2 (data not shown). The MIB-1 (monoclonal antibody against Ki-67; cell proliferation marker) labeling index was $10 \%$ in the hot spot (Fig. 2E). Almost all spindle-shaped cells were positive for BAF47 similar to the cells in non-tumor tissues, such as inflammatory cells and endothelial cells (Fig. 2F).

In addition, genomic rearrangements, such as $S S 18-S S X \mathrm{~s}$ (SS18-SSX1, SS18-SSX2, SS18-SSX4, SS18-SSX4V, SS18p-SSXp or SS18-SSXp) and MYH9-USP6s (MYH9 exon 1 and USP6 exon 1 or MYH9 exon 1 and USP6 exon 2), for differential diagnostic supports, were not detected (Fig. 2G). Total RNA was extracted from PFPE sections with the RNeasy FFPE kit (Qiagen GmbH, Hilden, Germany) according to the manufacturer's instructions. Five micrograms of RNA was reverse-transcribed using ReverTra Ace transcriptase (Toyobo 

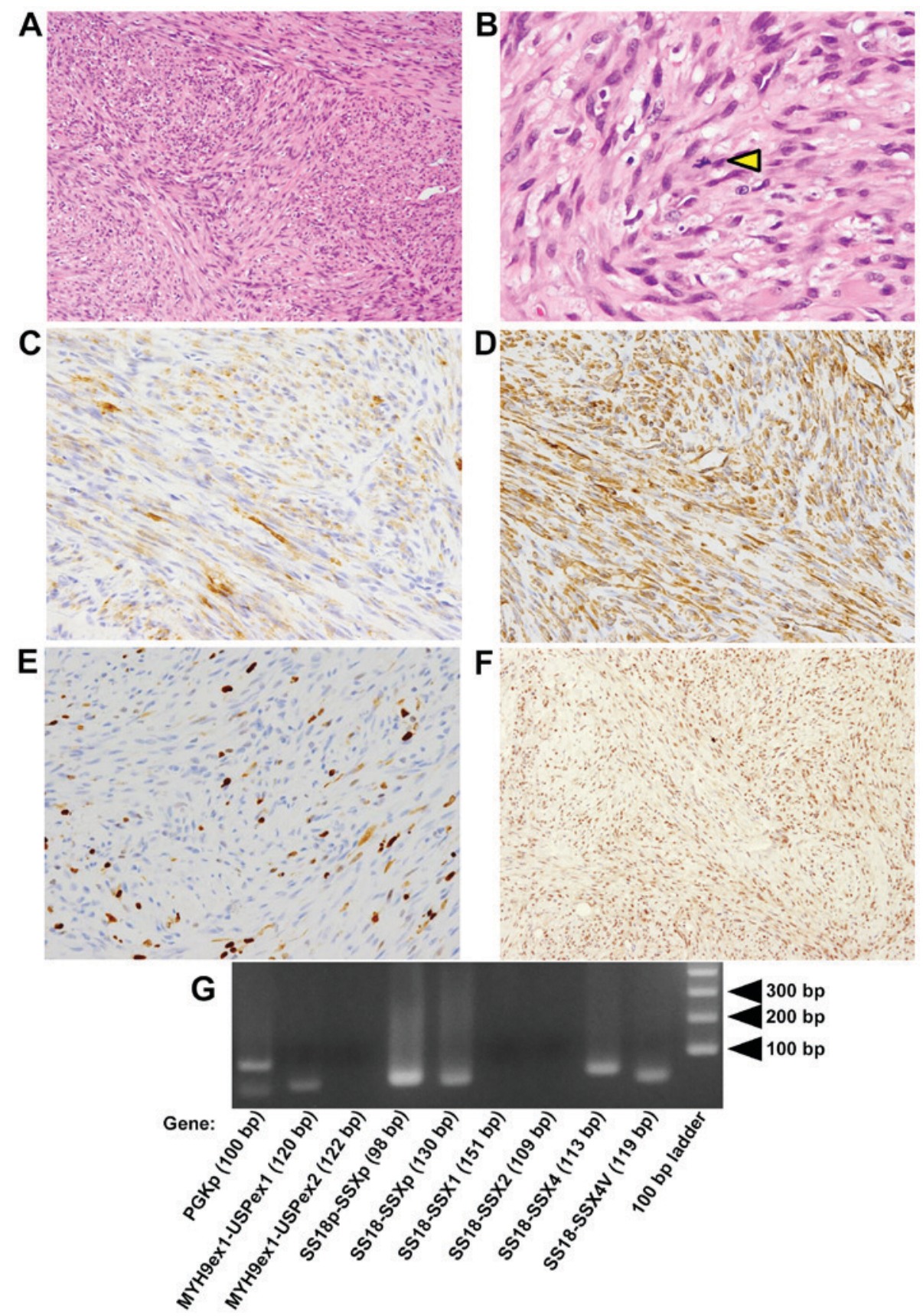

Figure 2. (A) Hematoxylin-eosin staining. (A) The proliferation of spindle-shaped cells with fascicular and/or storiform patterns is shown (magnification, $\mathrm{x} 100)$. (B) The triangle indicates a mitotic figure (magnification, $\mathrm{x} 400$ ). The cytoplasm of the tumor cells was stained for (C) $\alpha$-smooth muscle actin (magnification, x200) and (D) vimentin (magnification, x200). (E) Positivity for MIB-1 staining was noted in 10\% of the tumor cells (magnification, x200). (F) Almost all the spindle cells were positive for BAF47 (magnification, x200). (G) The result of polymerase chain reaction.

Life Science, Osaka, Japan) in order to prepare the first-strand cDNA. Each polymerase chain reaction (PCR) product $(10 \mu \mathrm{l})$ was directly loaded onto $2 \%$ agarose gel, stained with ethidium bromide, and directly visualized under UV illumination. Amplification of 100 base-pair (bp) products of PGKp was positive control of this PCR. Forward and reverse primers and annealing temperatures were summarized in Table I.

Furthermore, PCR amplification and sequencing analysis were carried out for assessing mutations. We extracted genomic DNAs from macrodissected PFPE sections using the WaxFree $^{\mathrm{TM}}$ Paraffin Sample DNA Extraction kit (Trimgen, Sparks Glencoe, MD, USA) according to the manufacturer's instructions (8). The mutational status of $A P C, C T N N B 1$ (9),
EGFR (10), KRAS, PIK3CA (11) and $p 53$ (12) genes was investigated using a PCR and direct sequencing, and no genetic mutations of these cancer-related genes were detectable. In Table II, forward and reverse primers for indicated exons in this sequencing analysis and annealing temperatures were shown. Copy number variations (CNVs) of the chromosomal intervals and/or candidate genes were not examined in the present study.

Several intravascular invasions of the tumor cells were found (Fig. 3A). Intravascular invading tumor cells were positive for vimentin (Fig. 3B). The vasculature was lined by CD34-positive vascular endothelial cells (Fig. 3C) and supported by $\alpha$-SMA-positive (Fig. 3D) muscular tissue. Furthermore, elastic fibers were positive for Elastica van Gieson (EVG) 
Table II. Forward and reverse primers for genetic mutation analysis of cancer-related genes.

\begin{tabular}{|c|c|c|}
\hline Gene & Primers & Product size (bp) \\
\hline APC-1-Exon 16 & $\begin{array}{l}\text { F: 5'-TAGGATGTAATCAGACGACAC-3' } \\
\text { R: 5'-CAGTCTGCTGGATTTGGTTC-3' }\end{array}$ & 152 \\
\hline APC-2-Exon 16 & $\begin{array}{l}\text { F: 5'-GAAGTTCCAGCAGTGTCACA-3' } \\
\text { R: 5'-GTGTTCAGGTGGACTTTTGG-3' }\end{array}$ & 162 \\
\hline APC-3-Exon 16 & $\begin{array}{l}\text { F: 5'-CAAAAGTGGTGCTCAGACAC-3' } \\
\text { R: 5'-TGCCACTTACCATTCCACTG-3' }\end{array}$ & 164 \\
\hline APC-4-Exon 16 & $\begin{array}{l}\text { F: 5'-TCCGTTCAGAGTGAACCATG-3' } \\
\text { R: 5'-GGTACTTCTCGCTTGGTTTG-3' }\end{array}$ & 149 \\
\hline APC-5-Exon 16 & $\begin{array}{l}\text { F: 5'-GTAAAACACCTCCACCACCT-3' } \\
\text { R: 5'-TCAGCATCTGGAAGAACCTG-3' }\end{array}$ & 151 \\
\hline APC-6-Exon 16 & $\begin{array}{l}\text { F: 5'-AATGCTGCAGTTCAGAGGGT-3' } \\
\text { R: 5'-CCTGAACTGGAGGCATTATTC-3' }\end{array}$ & 172 \\
\hline APC-7-Exon 16 & $\begin{array}{l}\text { F: 5'-CTCGATGAGCCATTTATACAG-3' } \\
\text { R 5'-AGGTCCTTTTCAGAATCAATAG-3' }\end{array}$ & 158 \\
\hline CTNNB1-Exon 3 & $\begin{array}{l}\text { F: 5'-GAAAAGCGGCTGTTAGTCAC-3' } \\
\text { R: 5'-GAGAAAATCCCTGTTCCCAC-3' }\end{array}$ & 133 \\
\hline EGFR-Exon 18 & $\begin{array}{l}\text { F: 5'-TGTCTCTGTGTTCTTGTCCC-3' } \\
\text { R: 5'-CCAGGGACCTTACCTTATAC-3' }\end{array}$ & 162 \\
\hline EGFR-Exon 19 & $\begin{array}{l}\text { F: 5'-GCCAGTTAACGTCTTCCTTC-3' } \\
\text { R: 5'-CCACACAGCAAAGCAGAAAC-3' }\end{array}$ & 157 \\
\hline KRAS-Exon 1 & $\begin{array}{l}\text { F: 5'-GGTACTGGTGGAGTATTTGA-3' } \\
\text { R: 5'-CAAGATTTACCTCTATTGTTGG-3' }\end{array}$ & 158 \\
\hline PIK3CA-Exon 20 & $\begin{array}{l}\text { F: 5'-AACTGAGCAAGAGGCTTTGG-3' } \\
\text { R: 5'-CTTTTCAGTTCAATGCATGCTG-3' }\end{array}$ & 122 \\
\hline p53-Exon 5 & $\begin{array}{l}\text { F: 5'-CTCTTCCTGCAGTACTCCCCTGC-3' } \\
\text { R: 5'-GCCCCAGCTGCTCACCATCGCTA-3' }\end{array}$ & 211 \\
\hline p53-Exon 6 & $\begin{array}{l}\text { F: 5'-GTGCAGCTGTGGGTTGATT-3' } \\
\text { R: 5'-GGCCACTGACAACCACCCTTAACC-3' }\end{array}$ & 182 \\
\hline p53-Exon 7 & $\begin{array}{l}\text { F: 5'-GCTTGCCACAGGTCTCCCCAAG-3' } \\
\text { R: 5'-AGGCTGGCAAGTGGCTCCTGAC-3' }\end{array}$ & 192 \\
\hline p53-Exon 8 & $\begin{array}{l}\text { F: 5'-TGGTAATCTACTGGGACGGA-3' } \\
\text { R: 5'-GCTTAGTGCTCCCTGGGGGC-3' }\end{array}$ & 134 \\
\hline p53-Exon 9 & $\begin{array}{l}\text { F: 5'-GCCTCTTTCCTAGCACTGCCCAAC-3' } \\
\text { R: 5'-CCCAAGACTTAGTACCTGAAGGGTG-3' }\end{array}$ & 102 \\
\hline
\end{tabular}

Annealing for all polymerase chain reaction products was performed at $60^{\circ} \mathrm{C}$, except for EGFR at $59^{\circ} \mathrm{C}, \mathrm{KRAS}$ at $59^{\circ} \mathrm{C}$ and $\mathrm{PIK} 3 \mathrm{CA}$ at $57^{\circ} \mathrm{C}$. $F$, forward; $R$, reverse.

staining (Fig. 3E). EVG staining was performed according to the standard protocol. The MIB-1 labeling index of the tumor cells noted in the vascular tissue was $2-10 \%$ (Fig. 3F). Since the histological findings showed a tumor-free region with 2-3 mm normal tissue in the extirpated sample, re-resection of the tongue was performed to obtain a tumor-free region with $10 \mathrm{~mm}$ normal tissue. The patient had no evidence of local recurrence or metastasis in the two and a half years since the first operation.

\section{Discussion}

LGMS is known to be a rare sarcoma tumor (1-3). In the head and neck region, LGMS frequently occurs in the tongue, especially in the lateral edge of the tongue (13) compared with that in the skin and gastrointestinal tract. To our knowledge, this is the first report of LGMS arising in the tip of the tongue. In the 2013 WHO classification, LGMS is an intermediate-rarely metastasizing tumor mainly composed of atypical myofibroblasts. Myofibroblasts share immunohistochemical and ultrastructural features of both fibroblasts and smooth muscle cells and play a role in wound and tissue repair (14). However, the function of myofibroblasts in LGMS has been unclear. LGMS tends to be found in local recurrence rather than metastasis (15). The current case showed a low MIB-1 labeling index in the tumor cells and several intravascular invasions of the tumor cells. The MIB-1 labeling index of the intravascular tumor cells was $2-10 \%$, which was almost the same as that in the original tumor (Fig. 3E). There has been no evidence of 

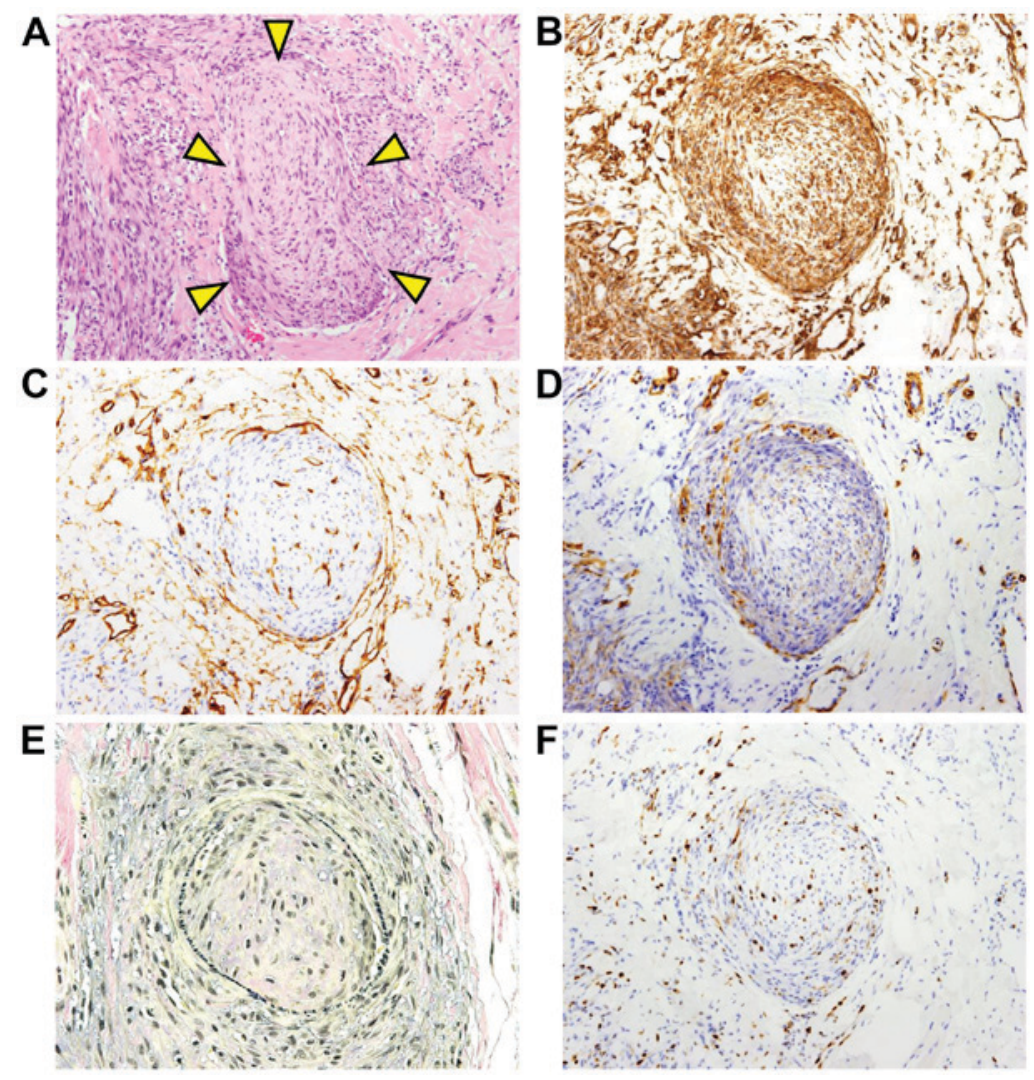

Figure 3. Intravascular invasion of LGMS tumor cells. (A) The triangles indicate the tumor cells invading into the vascular tissue. Hematoxylin-eosin staining (magnification, x100). (B) The intravascular invading tumor cells were stained with vimentin (magnification, x100). (C) The vascular endothelial cells were stained for cluster of differentiation 34 (magnification, x100). (D) The vasculature was surrounded by $\alpha$-smooth muscle actin-positive muscular tissue (magnification, x100). (E) The vascular elastic fibers were stained for Elastica van Gieson (magnification, x100). (F) The intravascular invading tumor cells were stained with MIB-1 antibody (magnification, x100). LGMS, low-grade myofibroblastic sarcoma.

local recurrence or metastasis in the two and a half years since the first operation. Therefore, these findings were consistent with the description by the WHO that LGMS has a malignant potential and is an intermediate-rarely metastasizing tumor.

The differential diagnosis of LGMS should include other spindle cell tumors, such as benign tumors; inflammatory myofibroblastic tumors and nodular fasciitis; such as intermediate tumor; desmoplastic fibroma or malignant tumors, such as synovial sarcoma (12), leiomyosarcoma and osteosarcoma (1). Inflammatory myofibroblastic tumor shows infiltration of inflammatory cells. As the genomic rearrangement of MYH9-USP6s (MYH9 exon 1 and USP6 exon 1 or MYH9 exon 1 and USP6 exon 2), which is frequently observed in nodular fasciitis (16), was not shown in the current case (data not shown), nodular fasciitis would be excluded. Synovial sarcoma would be ruled out, because reduced expression of BAF47 (INI1 gene product) protein (17), which is shown in synovial sarcoma, was not observed. Neither rhabdoid cells, which are characterized by the existence of a large eosinophilic inclusion within the cytoplasm, eccentric nuclei and prominent nucleoli, nor the genomic rearrangement of SS18-SSXs (SS18-SSX1, SS18-SSX2, SS18-SSX4, $S S 18-S S X 4 V$, SS18p-SSXp or SS18-SSXp) were detected in the case (Fig. 2G). In general, malignant tumor cells frequently show increased number of mitotic figures and point mutations of cancer-related genes. The tumor cells involved in the current LGMS showed no point mutations in the APC, CTNNBI, EGFR, KRAS, PIK3CA or p53 gene (data not shown). Many cases of leiomyosarcoma (18) and osteosarcoma (19) have been reported to have a gene mutation in $p 53$, and desmoplastic fibroma has a point mutation in CTNNB1. Therefore, point mutations of the investigated genes might not be involved in intravascular invasion of myofibroblasts in LGMS. Because there are no established treatments for LGMS at present, the mechanism underlying the invasion of atypical myofibroblasts into vascular tissue should be clarified in the future.

\section{Acknowledgments}

Not applicable.

\section{Funding}

The present study was supported by JSPS KAKENHI (2016-2018; grant no. JP16K11501) and (2017-2018; grant no. 17H06947).

\section{Availability of data and materials}

All data generated or analyzed during the present study are included in this published article.

\section{Author contributions}

YM performed the immunohistochemial experiments. YM and SF designed and wrote the manuscript. YM, MM, SK, 
and SN performed the clinical diagnosis, treatment (including resection of the tongue) and follow-up of the patient. KK, YY and $\mathrm{YO}$ performed the mutations and genomic rearrangements analysis. YM, SF, KK, YY, YO and KT made the histopathological diagnosis. KT interpreted results and co-wrote the manuscript.

\section{Ethics approval and consent to participate}

This study was approved by the Research Ethics Committee of Kyushu University (approval nos. 25-111, 26-257, 27-77 and 29-625). Written informed consent was obtained from the patient.

\section{Patient consent for publication}

Written informed consent was obtained from the patient for the publication of their data.

\section{Competing interests}

The authors declare that they have no competing interests.

\section{References}

1. Saito T, Mitomi H, Kurisaki A, Torigoe T, Takagi T, Suehara Y, Okubo T, Kaneko K and Yao T: Low-grade myofibroblastic sarcoma of the distal femur. Int J Surg Case Rep 4: 195-199, 2013

2. Roth TM, Fratkin J, Woodring TC and McGehee RP: Low-grade myofibroblastic sarcoma of the vulva. Gynecol Oncol 92: 361-364, 2004

3. San Miguel P, Fernández G, Ortiz-Rey JA and Larrauri P Low-grade myofibroblastic sarcoma of the distal phalanx. J Hand Surg Am 29: 1160-1163, 2004.

4. Yamada T, Yoshimura T, Kitamura N, Sasabe E, Ohno S and Yamamoto T: Low-grade myofibroblastic sarcoma of the palate. Int J Oral Sci 4: 170-173, 2013

5. Gabbiani G, Ryan GB and Majne G: Presence of modified fibroblasts in granulation tissue and their possible role in wound contraction. Experientia 27: 549-550, 1971.

6. Follonier L, Schaub S, Meister JJ and Hinz B: Myofibroblast communication is controlled by intercellular mechanical coupling. J Cell Sci 121: 3305-3316, 2008.
7. Mentzel T: Low-grade myofibroblastic sarcoma. In: Fletcher CDM, Bridge JA, Hogendoorn PCW, Mertens F (eds): World Health Organization Classification of Tumours: Pathology and genetics of tumours of soft tissue and bone. IARC Press: Lyon, France, pp85-86, 2013.

8. Fujii S, Shinjo K, Matsumoto S, Harada T, Nojima S, Sato S, Usami Y, Toyosawa S, Morii E, Kondo Y and Kikuchi A: Epigenetic upregulation of ARL4C, due to DNA hypomethylation in the 3'-untranslated region, promotes tumorigenesis of lung squamous cell carcinoma. Oncotarget 7: 81571-81587, 2016.

9. Kurihara S, Oda Y, Ohishi Y, Kaneki E, Kobayashi H, Wake N and Tsuneyoshi M: Coincident expression of beta-catenin and cyclin D1 in endometrial stromal tumors and related high-grade sarcomas. Mod Pathol 23: 225-234, 2010.

10. Nishijima T, Yamamoto H, Nakano T, Nakashima T, Taguchi K, Masuda M, Motoshita J, Komune S and Oda Y: Dual gain of HER2 and EGFR gene copy numbers impacts the prognosis of carcinoma ex pleomorphic adenoma. Hurn Pathol 46: 1730-1443, 2015.

11. Fujita K, Yamamoto H, Matsumoto T, Hirahashi M, Gushima M, Kishimoto J, Nishiyama K, Taguchi I, Yao T and Oda Y: Sessile serrated adenoma with early neoplastic progression: A clinicopathologic and molecular study. Am J Surg Pathol 35: 295-304, 2011.

12. Oda Y, Sakamoto A, Saito T, Kawauchi S, Iwamoto Y and Tstuneyoshi M: Molecular abnormalities of p53, MDM2, and H-ras in synovial sarcoma. Mod Pathol 13: 994-1004, 2000.

13. Demarosi F, Bay A, Moneghini L and Carrassi A: Low-grade myofibroblastic sarcoma of the oral cavity. Oral Surg Oral Med Oral Pathol Oral Radiol Endod 108: 248-254, 2009.

14. Tomasek JJ, Gabbianr G, Hinz B, Chaponnier C and Brown RA: Myofibroblasts and mechano-regulation of connective tissue remodelling. Nat Rev Mol Cell Biol 3: 349-363, 2002.

15. Niedzielska I, Janic T and Mrowiec B: Low-grade myofibroblastic sarcoma of the mandible: A case report. J Med Case Rep 3: 8458, 2009

16. Erickson-Johnson MR, Chou MM, Evers BR, Roth CW, Seys AR, Jin L, Ye Y, Lau AW, Wang X and Oliveira AM: Nodular fasciitis: A novel model of transient neoplasia induced by MYH9-USP6 gene fusion. Lab Invest 91: 1427-1433, 2011

17. Kohashi K, Oda Y, Yamamoto H, Tamiya S, Matono H, Iwamoto Y, Taguchi T and Tsuneyoshi M: Reduced expression of SMARCB1/INI1 protein in synovial sarcoma. Mod Pathol 23: 981-990, 2010.

18. Lee PJ, Yoo NS, Hagemann IS, Pfeifer JD, Cottrell CE, Abel HJ and Duncavage EJ: Spectrum of mutations in leiomyosarcomas identified by clinical targeted next-generation sequencing. Erp Mol Pathol 102: 156-161, 2017.

19. Overholtzer M, Rao PH, Favis R, Lu XY, Elowitz MB, Barany F, Ladanyi M, Gorlick R and Levine AJ: The presence of p53 mutations in human osteosarcomas correlates with high levels of genomic instability. Proc Natl Acad Sci USA 100: 11547-11552, 2003. 